\title{
Patterns of Intimate Partner Violence and Associated Risk Factors Among Married Enlisted Female Soldiers
}

\author{
Mary Ann Forgey, PhD \\ Lee Badger, PhD \\ Fordham University
}

\begin{abstract}
A sample of 248 enlisted active duty females married to civilian spouses completed a self-report survey that asked about their own and their spouse's violence. The survey also asked about their sex-role attitudes, marital satisfaction, alcohol use, childhood trauma, and depression. Results identified patterns of intimate partner violence and their relationship to the psychosocial risk factors. Females experiencing severe bidirectional violence were likely to be the most depressed and to have a history of child sexual abuse. Females experiencing minor bidirectional violence did not share any of the psychosocial risk factors found for severe bidirectional violence. Females perpetrating unilateral violence toward their spouses were found to be as satisfied in their marriages as nonviolent couples and less depressed than the females experiencing bidirectional violence.
\end{abstract}

Keywords: military women; enlisted females; domestic violence; spouse abuse; intimate partner violence; bidirectional violence

$\mathrm{W}$ hile there has been a significant amount of research on the intimate partner violence (IPV) perpetrated by active duty male soldiers married to civilian wives, there has been much less focus on IPV in the lives of married active duty females. The studies that do exist suggest active duty females may be at higher risk for being victims or perpetrators of IPV compared to civilian females and that active duty females married to civilian males may be facing unique risks.

\section{Active Duty Female IPV Victimization}

Based on analysis of the U.S. Army Central Registry, a data bank containing a confidential index of reported child and spouse abuse cases, McCarroll and colleagues (McCarroll, Thayer, et al., 2000) found that male civilian offenders (married to active duty females) had the highest rate of IPV recidivism (30\%) compared to male active duty offenders (27\%), female civilian offenders (20\%), and female active duty offenders (18\%). In addition to this evidence of IPV victimization, which is based only on reported cases of IPV, Campbell and colleagues (2003) found, in a cross-sectional study, a 30\% lifetime victimization rate for military females from all branches of the military, $58 \%$ of which reportedly occurred 
while on active duty. This lifetime prevalence rate for military women is much higher than the $21.7 \%$ lifetime prevalence rate found by Tjaden and Thoennes (2000) in their analysis of the National Violence Against Women Survey.

\section{Active Duty Female IPV Perpetration}

In contrast to the above findings on active duty IPV victimization rates, other studies report high rates of IPV perpetration on the part of active duty females. For example, McCarroll and colleagues (McCarroll, Ursano, et al., 2000), in an analysis of survey data of married active duty Army men and women from 47 Army installations, found higher percentages of moderate aggression (24\% vs. $18 \%$ ) and severe aggression ( $8 \%$ vs. $5 \%$ ) among female active duty personnel than the percentages among male active duty personnel, respectively.

The IPV perpetration rates for active duty females have also been found to be much higher than civilian females. Heyman and Neidig (1999) compared U.S. Army and civilian spouse abuse rates using representative samples after standardizing the Army sample so that it had comparable demographics to the civilian sample. Married active duty women reported significantly higher rates of wife to husband spousal aggression compared to the civilian sample on both moderate aggression (13\% vs. $10 \%$, respectively) and severe aggression ( $4.4 \%$ vs. $2.0 \%$, respectively).

\section{Pattern of Violence Within the Relationship}

Given the high IPV victimization and perpetration rates found for active duty females and the specific risk of IPV for active duty females married to civilian males, this study set out to provide more understanding about the IPV experience of this population. We were particularly interested in going beyond studying either the victimization or perpetration rates for this population by first developing more understanding about the pattern of violence experienced within each relationship. For an understanding of pattern, a critical distinction must be recognized, and that is the examination of the direction of the violence within the relationship. In other words, attention must focus on the level and type of violence committed or not committed by each partner. When the direction of the violence and other factors are considered, a much more complex picture of the patterns of IPV emerges. Based on this understanding of the pattern of violence within the relationship, we were then interested in examining the demographic and psychosocial risk factors associated with each pattern identified.

Within the civilian sector, an increasing number of recent studies using either national population or community samples have included directionality in the analysis (e.g., Capaldi \& Owen, 2001; Field \& Caetano, 2005; Kwong, Bartholomew, \& Dutton, 1999; Williams $\&$ Frieze, 2005). The most prevalent pattern found in these studies, based on national population or community samples, is bidirectional violence (Caetano, Ramisetty-Mikler, \& Field, 2005; Field \& Caetano, 2005). In studies that have differentiated high- and lowlevel bidirectional violence, low level bidirectional violence has been found to be the most prevalent pattern (Capaldi \& Owen, 2001; Kwong et al., 1999; Williams \& Frieze, 2005). Some studies have made further distinctions within bidirectional violence based on the level of violence committed by each partner toward the other. One type of violence has been termed asymmetrical. In this pattern, the partner committing the higher level of violence was labeled the primary perpetrator (Kernsmith, 2005; Temple, Weston, \& Marshall, 2005; Vivian \& Langhinrichsen-Rohling, 1994; Williams \& Frieze, 2005).

Military IPV research that has gone beyond the reporting of separate victimization and perpetration rates by including directionality has been limited. Only one study (McCarroll, 
Ursano, Fan, \& Newby, 2004), in addition to the one described in this article, is instructive about the experience of active duty women. McCarroll's study analyzed Army Central Registry data to determine changes in directionality within abuse patterns from 1998 to 2002. In 1998, the numbers of unilateral (male to female) and bidirectional cases for married active duty females were equivalent, but by 2002 the unilateral abuse cases had increased twofold. McCarroll also found that the active duty females married to civilian males had the highest risk of becoming a victim of unilateral abuse compared to both active duty males married to civilian females and dual military couples. Two earlier clinical studies (Cantos, Neidig, \& O'Leary, 1994; Langhinrichsen-Rohling, Neidig, \& Thorn, 1995) of active duty personnel with civilian spouses found high rates (e.g., 83\%) of bidirectional violence among the couples. However, the findings did not differentiate active duty males from active duty females.

\section{Summary of the Initial Findings on the Patterns of Violence}

In an earlier article using the same sample of enlisted active duty females married to civilian spouses presented here (Forgey \& Badger, 2006), we identified the patterns of violence that emerged. We also investigated whether there were general demographic or specific military characteristics associated with these patterns of violence. Since our findings reported in this article on the psychosocial risk factors associated with the various patterns build upon this earlier investigation, ${ }^{1}$ a brief description of the six pattern groups follows:

- Group 1: No Violence was comprised of all nonviolent couples.

- Group 2: Bidirectional Symmetrical Severe Violence or Injury included all cases in which the enlisted female reported that both she and her spouse had both engaged in severe violence (physical, sexual, psychological) toward each other and/or that both had been physically injured.

- Group 3: Bidirectional Symmetrical Severe Psychological Aggression Only included all cases in which the enlisted female reported that both she and her spouse had both engaged in severe psychological aggression toward each other, without additional physical or sexual violence or physical injury.

- Group 4: Bidirectional Symmetrical Minor Physical and/or Sexual Violence included all cases in which the enlisted female reported that both she and her spouse had both engaged in minor physical and/or sexual violence toward each other and that neither had been injured in any way.

- Group 5: Female perpetrator-Unilateral/Bidirectional Asymmetrical included all cases in which the enlisted female reported that she alone had been violent toward her spouse (female unilateral) or that she had engaged in a more severe form of violence toward him than he had committed toward her (bidirectional asymmetrical).

- Group 6: Male perpetrator-Unilateral/Bidirectional Asymmetrical included all cases in which the enlisted female reported that her spouse alone had been violent toward her (male unilateral) or that her spouse had committed a more severe form of violence toward her than she had committed toward him (bidirectional asymmetrical).

The size of each of the six violence pattern groups is shown in Table 1.

\section{Psychosocial Risk Factors}

This article attempts to describe more fully the enlisted female's experience of IPV by identifying the psychosocial risk factors that were found to be associated with the different patterns of violence described above. A great deal of IPV risk factor research has 
TABLE 1. Unilateral and Bi-Directional Violence Pattern by Type and Severity

\begin{tabular}{|c|c|c|c|c|}
\hline \multirow[b]{2}{*}{ Group } & \multirow[b]{2}{*}{ Violence Pattern, Type, and Severity } & \multicolumn{2}{|c|}{ Sample } & \multirow{2}{*}{$\begin{array}{c}\% \text { of } \\
\text { Violence }\end{array}$} \\
\hline & & $N$ & $\%$ & \\
\hline 1 & No Violence & 100 & 40.3 & 0 \\
\hline 2 & $\begin{array}{l}\text { Bi-directional Symmetrical }{ }^{\text {a }} \text { Severe } \\
\text { Violence and/or Injury }\end{array}$ & 28 & 11.3 & 19.0 \\
\hline 3 & $\begin{array}{l}\text { Bi-directional Symmetrical }{ }^{\text {a }} \text { Severe } \\
\text { Psychological Aggression only }\end{array}$ & 11 & 4.4 & 7.0 \\
\hline 4 & $\begin{array}{l}\text { Bi-directional Symmetrical }{ }^{\text {a }} \text { Minor } \\
\text { Sexual and/or Physical Violence }\end{array}$ & 51 & 20.6 & 34.0 \\
\hline 5 & $\begin{array}{l}\text { Female Perpetrator } \\
\text { Unilateral/Bi-directional Asymmetrical }\end{array}$ & 16 & 6.5 & 11.0 \\
\hline \multirow[t]{2}{*}{6} & $\begin{array}{l}\text { Male Perpetrator } \\
\text { Unilateral/Bi-directional Asymmetrical }\end{array}$ & 42 & 16.9 & 28.0 \\
\hline & Total & 248 & 100 & 100 \\
\hline
\end{tabular}

aThe greatest proportion of partners in all bi-directional abuse groups both committed violence in the 1-6 frequency range (Severe Physical, 68\%; Severe Sexual, 89\%; Severe Psychological, 50\%). Eighteen percent of both partners committed violence over 15 times in the past year (Severe Psychological Only, 73\%; Minor Physical, 84\%; and Minor Sexual, $77 \%$ ). The frequency of violence was far more often equivalent for both partners than otherwise.

accumulated over the past 30 years. The majority of this risk factor research has been based on studies that seek to understand male violence toward the female partner and to a much lesser extent female-to-male violence. Only until very recently have there been studies that have examined the risk factors that distinguish unilateral versus bidirectional patterns, as this study attempts to do (Caetano et al., 2005; Temple et al., 2005).

The risk factors, childhood trauma, alcohol use, marital satisfaction, and depression, selected for inclusion in this study have all been found to be risk factors for male partner aggression in both general population and married active duty male samples (e.g., Barnett \& Fagan, 1993; Hotaling \& Sugarman, 1986; Langhinrichsen-Rohling et al., 1995; O’Leary, Malone, \& Tyree, 1994; Pan, Neidig, \& O’Leary, 1994; Schuerger \& Reigle, 1988). Significant associations between female partner aggression and childhood physical abuse, child sexual abuse, and alcohol abuse were also beginning to emerge (Hamberger \& Potente, 1994; Langhinrichsen-Rohling et al., 1995; Magdol et al., 1997; Magdol, Moffitt, Caspi, \& Silva, 1998).

Another risk factor selected for inclusion in this study, sex-role egalitarianism, has been identified in general population studies as both a risk factor and protective factor, depending on the level of sex-role egalitarianism. Defined as an attitude that enables one to respond to another individual independent of that other individual's gender, several studies have found that men who abuse their female spouses tend to be less egalitarian and more traditional than nonabusive men (Bernard \& Bernard, 1983; Bernard, Bernard, \& Bernard, 1985). Crossman, Stith, and Bender (1990) found that a low level of egalitarianism was a risk factor only for men who committed acts of severe violence but not for men involved 
in minor violence. Consistent with this finding, Stith and Farley (1993) found sex-role egalitarianism to be a protective factor, that is, to have a direct negative effect on the use of severe violence in intimate relationships.

Sex-role egalitarianism was considered to be potentially relevant to the active duty female married to a civilian male. In this type of marital relationship, much gender role reversal occurs due to the female partner's military obligations. For example, the male civilian spouse is often in the role of following the wife's employment and having more responsibility for the children, particularly during deployments. The 1995 Survey of Army Families found that male civilian spouses have difficulty in some of the reversed roles, including managing household and child-related tasks (Marshall-Mies, 1996). This gender role reversal is also occurring in a male-dominated context, which may impact on the amount of support available to both spouses who find themselves in reversed gender roles. For the purposes of this study, we wanted to understand if there was a relationship between the enlisted female's sex-role attitudes and her experience of IPV.

How well the above established risk factors correlate with the six patterns of IPV identified in our previous study was the major line of inquiry for this study. Since this specific population (active duty enlisted females married to civilian spouses) had not yet been studied directly in relation to the above risk factors, the findings from this study provide important new knowledge.

\section{METHODS}

\section{Participants}

Data were collected from enlisted active duty U.S. Army females married to civilian spouses stationed at a large Army installation during the summer of 2001.

\section{Procedures}

A letter from the installation commander was mailed to every enlisted female married to a civilian spouse inviting them to attend an informational session about the study. At the informational session for prospective participants, the purpose of the study was explained and the enlisted females were invited to participate. Emphasis was placed on the voluntary nature of participation and that there would be no negative repercussions if they chose not to fill out a questionnaire. Those enlisted females who chose to participate were then asked to sign an informed consent. The questionnaires were given out and collected as soon as the participants completed them. The questionnaires were anonymous. All study procedures were reviewed and approved by the University IRB. The military, which concurred with the University IRB approval, requested no additional review.

\section{Measures}

Demographics. Demographic measures included both military-related variables (paygrade, military occupational specialty (MOS), years/months in the military, on- or off-base housing, length of time at the installation, number of work hours, weeks away from the installation on temporary duty in the past year, and weeks deployed in the past year), as well as descriptive demographic variables (both enlisted member's and spouse's age, race, education level, number of years married, number of children, and spouse's employment status and income level). 
Conflict Tactics Scale 2. The Conflict Tactics Scale 2 (CTS2) is a self-report measure of the violence both experienced and committed by the person completing the instrument (Straus, 1990b; Straus, Hamby, Boney-McCoy, \& Sugarman, 1996). The CTS2 is a revised version of the original CTS scale (Straus, 1990a), and unlike the original, contains measures of sexual coercion and injury. The internal consistency reliabilities have ranged from $\alpha=.79$ to $\alpha=.95$. There is also evidence of construct validity and discriminate validity (Straus et al., 1996).

The CTS2 includes 39 items within five types of violence subscales: Negotiation (6 items), Psychological Aggression (8 items), Physical Assault (12 items), Sexual Coercion ( 7 items $),{ }^{2}$ and Injury Inflicted (6 items), scored by 0-6 ( $0=$ never happened to $6=$ more than 20 times in the past year) Likert-type scales. The items in each subscale are further separated into minor and severe levels of conflict. Each item is measured twice (total items $=78$ ), once to reflect tactics used by the respondent (in this case, the enlisted female) and the other to reflect tactics used by the respondent's partner (in this case, her civilian spouse). Thus, scores can be obtained for each partner. The CTS2 may be scored in two ways: (1) a prevalence score for each subscale indicates whether or not that type and level of violence occurred within the past year, and (2) a chronicity score indicates the frequency of occurrence of that type and level of violence over the past year.

In this study, the active duty female filled out the CTS2 about her own violence in the relationship and her spouse's violence in accordance with the purpose of the scale. This one partner as informant method has been shown to be a reliable and suitable method for use in research on partner violence as long as the research conditions guarantee confidentiality (Moffit et al., 1997), which this study did.

Short Marital Adjustment Test (SMAT). Marital satisfaction and discord were measured using the SMAT, which is a widely used self-report measure assessing global marital satisfaction with reliability of $\alpha=.90$ (Locke \& Wallace, 1959). It has been shown to discriminate distressed from nondistressed couples in numerous studies (O'Leary, Arias, \& Saminos, 1987).

Sex-Role Egalitarianism Scale (SRE). Sex-role egalitarianism was measured using a shortened version of the SRE Scale, which measures predisposition to respond to another independent of one's gender (Beere, King, Beere, \& King, 1984; King \& King, 1997). The shortened version of the SRE (25 items) was used for this study (Rosenfeld \& Jarrard, 1985). Stith (1986) reported internal consistency reliability of $\alpha=.89$ for this shorter scale. High scores represent more egalitarian attitudes.

Short Michigan Alcoholism Screening Test (SMAST). The shorter version (25 items) of the Michigan Alcoholism Screening Test (MAST) was used in this study and is designed to provide rapid and effective screening for alcohol-related problems and alcoholism (Selzer, Vinokur, \& Van Rooijen, 1975). The scale has a range of questions assessing drinking behavior, negative repercussions of drinking, and efforts to seek help for one's drinking behavior. The SMAST has a reported alpha coefficient of .96 among a sample of alcoholics and nonalcoholics (Selzer et al., 1975).

Childhood Trauma Questionnaire (CTQ). The history of violence in the family of origin was measured using the CTQ (Bernstein \& Fink, 1998; Bernstein et al., 1994). Strong support exists for its reliability and validity. Principal components analysis of responses on the CTQ yielded four rotated orthogonal factors: physical and emotional abuse, emotional neglect, sexual abuse, and physical neglect. Cronbach's alpha for the factors ranged from .79 to .94 . The CTQ also demonstrated good test-retest reliability over a 2- to 6-month interval (intraclass correlations $=0.88$ ) indicating that the subject's reports of child abuse and neglect based on the CTQ were highly stable over time (Bernstein et al., 1994). 
Zung Self Rating Depression. Depression was measured using the Zung Self Rating Depression Scale (Zung, 1965). The Zung is a 20-item scale, with 4 choice response options for each item, specific to psychological depression. In the initial testing of this scale, the mean indices achieved on the scale for patients diagnosed with depressive disorders before and after treatment were .74 and .39 , respectively. The maximum score is .80 . The mean index for the control group was .33 .

\section{RESULTS}

In the analyses that follow, the enlisted female is the source of information about her own violence and her spouse's violence, as well as her own risk factors. A total of 248 enlisted females participated in the study. This number represents $18 \%$ of enlisted females married to civilian spouses at the installation study site. Approximately 5\% of the enlisted females who attended the informational sessions chose not to participate in the study.

The average age of the participating enlisted females was $29.8(S D=7.0)$ and the average age of their spouses was $31.8(S D=8.2)$. Over half of the sample $(51 \%)$ held the rank of E-4 or E-5; the remainder held higher ranks. ${ }^{3}$ Forty percent of the enlisted female sample was Black, $37 \%$ were White, $11 \%$ were Hispanic, $5 \%$ were Asian Pacific, $3 \%$ were Native American, and $4 \%$ indicated another origin. The average number of years married was 6.2 $(S D=5.4)$ and the average length of time in the service was $7.1(S D=6.2)$ years. Fifty-two percent of the enlisted female sample had a high school diploma, 35\% had an associates degree, and $7.3 \%$ had a bachelors degree or higher. Seventy-six percent of their spouses were reported to have a GED or high school diploma, 17\% an associate degree, and 5.6\% had a bachelor or graduate degree.

Comparison of the enlisted female sample age and military grade to both the installation population and the Army-wide population of enlisted females married to civilian spouses suggests that the study participants were relatively representative of these target populations with the following exceptions: in relation to race/ethnicity, the Black enlisted females were underrepresented in the sample (40\%) compared to both the installation population $(51 \%)$ and to the Army-wide population (48\%). The sample population was also considerably more educated than both the installation and Army-wide population. Thirty-five percent of the sample had an associate degree compared to only $8.9 \%$ of the installation population and $11 \%$ of the Army-wide population of enlisted females married to civilian spouses.

\section{Psychosocial Risk Factors and Patterns of Violence}

The purpose of this article was to examine the relationships between selected psychosocial risk factors to the six violence groups identified in our previous study. The psychosocial risk factors of interest were childhood physical and emotional abuse, emotional neglect, sexual abuse, and physical neglect, and the concurrent factors, (i.e., unknown as to their temporal relationship with violence), enlisted female alcohol use, sex-role egalitarianism, marital satisfaction, and depression.

\section{Childhood Abuse}

Childhood Trauma subscales scores were categorized into severity levels (none, low, moderate, severe), as recommended by the scale authors (Bernstein \& Fink, 1998). The relationships between each type of childhood trauma and the six violence groups were tested using chi-square analyses. Regarding childhood emotional abuse, $57 \%$ of the women in the total 
sample reported having experienced no, or very low, childhood emotional abuse. However, in IPV Violence Group 4 (Bidirectional Minor Physical and/or Sexual Abuse), just over half of all women reported to have experienced at least low levels of childhood emotional abuse and $28 \%$ of them had experienced it in a severe form $\left(\chi^{2}=25.5, p=.043\right.$; see Table 2 ). More notable, however, is the association between the IPV violence groups and childhood sexual abuse. While the analysis for the enlisted women found no significant associations between the none, low, moderate, or severe childhood sexual abuse categories and the IPV violence groups, when we dichotomized female childhood sexual abuse into "none or "some," significant associations were found among the groups. Almost three-quarters (73\%) of the IPV Violence Group 4 (Severe Psychological Only) and almost two-thirds $(65 \%)$ of women in IPV Violence Group 2 (Bidirectional Severe Assault or Injury) experienced childhood sexual abuse compared to $35 \%$ in the No Violence Group 1 (Table 3). It is also important to highlight the rather high prevalence rate (44\%) of some child sexual abuse experience reported by all of the enlisted females in this sample.

Dichotomizing the remaining Childhood Trauma scales for physical abuse, physical neglect, and emotional neglect in the same way as the scale for female child sexual abuse above did not reveal any significant associations with particular IPV Violence Groups. However, a significant association did emerge between the dichotomized childhood neglect and the commitment of some form of IPV. Sixty-eight percent of all enlisted females who

TABLE 2. Cross-Tabulation of Enlisted Female Childhood Emotional Abuse and Violence Groups

\begin{tabular}{|c|c|c|c|c|c|c|c|c|c|c|}
\hline \multirow[b]{3}{*}{ Violence Group } & \multicolumn{10}{|c|}{ Female Childhood Emotional Abuse } \\
\hline & \multicolumn{2}{|c|}{ Minimal } & \multicolumn{2}{|c|}{ Low } & \multicolumn{2}{|c|}{ Moderate } & \multicolumn{2}{|c|}{ Severe } & \multicolumn{2}{|c|}{ Total } \\
\hline & $N$ & $\%$ & $N$ & $\%$ & $N$ & $\%$ & $N$ & $\%$ & $N$ & $\%$ \\
\hline Group 1: No Violence & 67 & 67 & 10 & 10 & 10 & 10 & 13 & 13 & 100 & 100 \\
\hline \multicolumn{11}{|l|}{ Bi-directional } \\
\hline $\begin{array}{l}\text { Group 2: Severe } \\
\text { Violence or Injury }\end{array}$ & 12 & 43 & 10 & 36 & 1 & 4 & 5 & 18 & 28 & 100 \\
\hline $\begin{array}{l}\text { Group 3: Severe } \\
\text { Psychological }\end{array}$ & 5 & 46 & 4 & 36 & - & - & 2 & 18 & 11 & 100 \\
\hline $\begin{array}{l}\text { Group 4: Minor } \\
\text { Physical and/or } \\
\text { Sexual }\end{array}$ & 25 & 49 & 6 & 12 & 6 & 12 & 14 & 28 & 51 & 100 \\
\hline \multicolumn{11}{|l|}{ Unilateral } \\
\hline $\begin{array}{l}\text { Group 5: By } \\
\text { Enlisted Female }\end{array}$ & 10 & 62 & 2 & 13 & 2 & 13 & 2 & 13 & 16 & 100 \\
\hline $\begin{array}{l}\text { Group 6: By } \\
\quad \text { Civilian Spouse }\end{array}$ & 23 & 55 & 6 & 14 & 7 & 17 & 6 & 14 & 42 & 100 \\
\hline Total & 142 & 57 & 38 & 15 & 26 & 11 & 42 & 17 & 248 & 100 \\
\hline
\end{tabular}

$\chi^{2}=25.5, p=.043$. 
TABLE 3. Cross-Tabulation of Dichotomized Enlisted Female Childhood Sexual Abuse and Violence Groups

\begin{tabular}{|c|c|c|c|c|c|c|}
\hline \multirow[b]{3}{*}{ Violence Group } & \multicolumn{6}{|c|}{ Female Childhood Sexual Abuse } \\
\hline & \multicolumn{2}{|c|}{ None } & \multicolumn{2}{|c|}{ Some } & \multicolumn{2}{|c|}{ Total } \\
\hline & $N$ & $\%$ & $N$ & $\%$ & $N$ & $\%$ \\
\hline Group 1: No Violence & 65 & 65 & 35 & 35 & 100 & 100 \\
\hline \multicolumn{7}{|l|}{ Bi-directional } \\
\hline Group 2: Severe Violence or Injury & 10 & 36 & 18 & 65 & 28 & 100 \\
\hline Group 3: Severe Psychological & 3 & 27 & 8 & 73 & 11 & 100 \\
\hline Group 4: Minor Physical and/or Sexual & 32 & 63 & 19 & 37 & 51 & 100 \\
\hline \multicolumn{7}{|l|}{ Unilateral } \\
\hline Group 5: By Enlisted Female & 9 & 56 & 7 & 44 & 16 & 100 \\
\hline Group 6: By Civilian Spouse & 21 & 50 & 21 & 50 & 42 & 100 \\
\hline Total & 140 & 57 & 108 & 44 & 248 & 100 \\
\hline
\end{tabular}

$\chi^{2}=13.2, p=.02$.

reported to have experienced emotional neglect as a child also reported that they had committed some form of IPV toward their spouses $\left(\chi^{2}=7.8, d f=1, p=.004\right)$.

\section{Sex-Role Egalitarianism}

Analysis next turned to the concurrent sex role egalitarianism. Using ANOVA, on which the overall sample mean score was 87.6, there were no significant differences among the means of the six Violence Groups on sex-role egalitarianism, despite the role reversal so unique to this sample. When the SRES scores, which ranged from 42 to 130 , were categorized into four roughly equal percentages of women (42 through $65=24 \%, 66$ through 90 $=28 \%, 91$ through $108=24 \%$, and 109 through $130=24 \%$, respectively), chi-square analyses showed no significant relationships between levels of females' sex-role attitude scores and either her perpetration of violence (Violence Groups 2 through 5) or her victimization by unilateral violence (Violence Group 6).

\section{Alcohol Use}

Because the SMAST scores measuring drinking behavior were not normally distributed, we recoded the SMAST scores into the following three categories: minimal alcohol use (SMAST scores of 0 or $1=81 \%$ ), moderate alcohol use (SMAST score of $2=11 \%$ ), and greater than moderate alcohol use (SMAST scores of 2 or greater $=8 \%$ ). The female's drinking behavior was not statistically significantly related to any of the violence pattern groups. There was also no statistically significant relationship between the female's drinking, either by drinking versus not drinking (yes or no) or by amount of drinking (minimal, moderate, greater than moderate), and involvement in any violence, whether as perpetrator or as victim. 


\section{Depression}

The enlisted female completed the Zung Scale about her symptoms of depression. As shown in Table 4, the mean depression scores of Group 2 (Bidirectional Symmetrical Severe Violence and/or Injury) were significantly higher than all other violence group mean scores. The mean score for Group 4 (Bidirectional Symmetrical Minor Violence) was significantly greater only than Group 1 (No Violence Group). Most surprisingly, the women in the Unilateral Female Violence Group (5) scored as low on depression as the nonviolent group. It should be noted, however, that all mean scores in this study were higher than the mean score of .33 in the normative Zung sample. In other words, these women, in all of the pattern groups, were to some extent depressed, some more than others. However, given the cross-sectional design of this study, it is not clear if depression was an antecedent or consequence, or both, of the violence.

\section{Marital Satisfaction}

With regard to marital satisfaction (see Table 4), the women in the Unilateral Female Violence Group (5) scored the highest on the Marital Satisfaction measure, although this was statistically significantly higher only than Group 2 (Bidirectional Severe Violence).

An appropriate further statistical step in the analysis of these risk factors, for example, multinomial logistic regression, was precluded by insufficient sample power. These bivariate results nonetheless reveal important relationships between violence risk factors and patterns of violence that merit further study.

TABLE 4. One-Way ANOVA of Psychological Risk Factors by Violence Group

\begin{tabular}{|c|c|c|c|c|}
\hline \multirow[b]{3}{*}{ Violence Group } & \multicolumn{4}{|c|}{ Risk Factors } \\
\hline & \multicolumn{2}{|c|}{ Depression } & \multicolumn{2}{|c|}{ Marital Satisfaction } \\
\hline & $M$ & $S D$ & $M$ & $S D$ \\
\hline Group 1: No Violence & $.44^{\mathrm{a}}$ & .10 & $114.92^{\mathrm{a}, \mathrm{d}, \mathrm{e}}$ & 34.85 \\
\hline \multicolumn{5}{|l|}{ Bi-directional } \\
\hline $\begin{array}{l}\text { Group 2: Severe Violence or } \\
\text { Injury }\end{array}$ & $.60^{c}$ & .12 & $76.97^{\mathrm{b}-\mathrm{d}}$ & 36.85 \\
\hline Group 3: Severe Psychological & $.46^{\mathrm{a}, \mathrm{b}}$ & .12 & $100.03^{\mathrm{a}-\mathrm{e}}$ & 36.57 \\
\hline $\begin{array}{l}\text { Group 4: Minor Physical and/ } \\
\text { or Sexual }\end{array}$ & $.51^{\mathrm{b}}$ & .10 & $94.32^{\mathrm{d}, \mathrm{e}}$ & 40.05 \\
\hline \multicolumn{5}{|l|}{ Unilateral } \\
\hline Group 5: By Enlisted Female & $.44^{\mathrm{a}, \mathrm{b}}$ & .10 & $117.22^{\mathrm{a}, \mathrm{b}, \mathrm{e}}$ & 20.98 \\
\hline Group 6: By Civilian Spouse & $.51^{\mathrm{b}}$ & .12 & $87.62^{\mathrm{b}-\mathrm{e}}$ & 37.37 \\
\hline$F$ & \multicolumn{2}{|c|}{$8.7 * * *$} & \multicolumn{2}{|c|}{7.6 *** } \\
\hline
\end{tabular}

Note. Using Tukey HSD, means with different superscripts differ significantly $* * * p<.001$. For example, Group 1 (superscript a) differs significantly from Group 2 (superscript c) but not from Group 3 or Group 5, both of which also have superscript a. 


\section{DISCUSSION}

In our first article (Forgey \& Badger, 2006), we identified six distinct patterns of violence experienced by the enlisted female and found general and military-specific demographic differences between certain patterns. In this present article, we examined the differences in the female's psychosocial risk factors between these patterns. Among the females experiencing bidirectional violence, those experiencing it in a severe way were likely to be the most depressed and to have a history of child sexual abuse. Females experiencing minor bidirectional violence did not share any of the psychosocial risk factors found for severe bidirectional violence. Females perpetrating unilateral violence toward their spouses, while comprising only a small proportion of all violence (11\%) in this study were found to be as satisfied in their marriages as nonviolent couples and less depressed than the females experiencing bidirectional violence.

Some of our risk factor findings further validate findings from previous studies using civilian samples that explored the relationship of psychosocial risk factors and IPV patterns. However, since our study further differentiated bidirectional violence by type and level, it provided increased understanding about the relationship of certain risk factors to certain patterns. For example, while Caetano and colleagues (2005) also found female childhood sexual abuse to be a risk factor for bidirectional violence in a civilian sample, they did not differentiate between minor and severe bidirectional patterns. In our study, female childhood sexual abuse was found to be a risk factor only for bidirectional severe violence and bidirectional severe psychological abuse, but not for bidirectional minor violence.

Our finding of a significant relationship between enlisted female depression and severe bidirectional violence also validates findings from previous civilian studies. Temple et al. (2005) found that women in severe bidirectional violence relationships had significantly higher depression scores than the women in all of the other groups, indeed higher than those in either of the unidirectional violent (male or female) relationships. In our study, we also found that enlisted women who committed unilateral violence were no more depressed than nonviolent women and also tended to be more contented in their marriages than all other groups. Given these consistent findings between depression and severe bidirectional violence, more understanding is needed through longitudinal studies about its role as an antecedent or consequent.

The absence of any significant findings for alcohol consumption suggests that active duty females' risk profile for IPV may be different from males, both civilian and military, and from civilian females, where alcohol has been found to play a role in both IPV violence victimization and perpetration (Bell, Hartford, McCarroll, \& Senior, 2004; Caetano et al., 2005; Hotaling \& Sugarman, 1986; Pan et al., 1994; Shumacher, Feldbau-Kohn, Slep, \& Heyman, 2001).

A low level of sex-role egalitarianism was not related to the active duty female's violence perpetration or victimization risk. Likewise, a high level of sex-role egalitarianism did not protect her in anyway from involvement in IPV. The lack of findings with regard to SRE in our study provides further evidence that the risk factor profile for active duty female perpetrators of violence is different from civilian male perpetrators of IPV. In the latter, a low level of sex-role egalitarianism has been found to be a risk factor for severe IPV perpetration and a high level of SRE has been found to be a protective factor (Crossman et al., 1990; Stith \& Farley, 1993). It is important to note, however, that we do not know if the SRE level of the civilian spouse was related to any of IPV violence patterns identified in this study, since our study was focused on the active duty female's risk factors. 


\section{Strengths and Limitations of the Study}

One of the strengths of this study is the distinction made between minor and severe bidirectional violence and the different female risk factor relationships found for each of these patterns. Our results provide evidence that minor and severe bidirectional violence are distinct patterns that need to be differentiated within IPV research.

Due to our selection of the CTS2 to measure the violence, some potentially important violence factors could not be included in our analysis of the patterns of violence. Although the CTS2 is the most widely used and validated measure of the prevalence of IPV, it does not measure motives (e.g., control, self-defense) or emotional impact of violence (e.g., fear, guilt). This limitation must be taken into consideration when interpreting any findings based on the CTS2. For example, if we had asked participants about the emotional impact of the violence (e.g., extent of fear experienced) and the motives involved (e.g., selfdefense), some of the cases sorted into the bidirectional symmetrical group could possibly have warranted inclusion in the asymmetrical group instead.

While we were pleased with the extent to which we were able to measure the risk factor of childhood abuse using the CTQ scale (Bernstein \& Fink, 1998), the witnessing of IPV as a child is not measured in this scale. We now see this as a real omission in our risk factor analysis, particularly in light of the finding that observing parental violence is a risk factor for female to male unilateral violence (Caetano et al., 2005).

Another risk factor that was not examined in this study, but needs to be included in future studies of IPV for this population, is adult sexual trauma outside of the marital relationship. Several studies conducted subsequent to our study have found alarmingly high prevalence rates of adult sexual trauma for active duty females (e.g., Bostock \& Daley, 2007; Hansen \& Summers, 2005). While our study did examine childhood sexual abuse and sexual abuse within the marital relationship, we did not examine adult sexual trauma outside of the marital relationship. Given the high prevalence rates now being found, a better understanding of the relationship between adult sexual trauma outside of the marital relationship and IPV is critical.

Our study was conducted prior to the American military's involvement in the Afghanistan and Iraq conflicts and, therefore, importantly serves as a prewar baseline. Since that time, two combat-related risk factors, Post Traumatic Stress Disorder (PTSD) and Traumatic Brain Injury (TBI), are receiving increased attention due to the high prevalence of PTSD and TBI among soldiers returning from deployment (Hoge et al., 2004; Warden, 2006). Given the relationship of combat-related PTSD and the perpetration of domestic violence that has been found among veterans from earlier conflicts, most notably Vietnam (Beckham, Feldman, Kirby, Hertzberg, \& Moore, 1997; Carroll, Rueger, Foy, \& Conahoe, 1985; Orcutt, King, \& King, 2003), and the existing civilian research on the relationship between TBI and IPV perpetration (Cohen, Rosenbaum, Kane, Warnken, \& Benjamin, 1999; Marsh \& Martinovich, 2006; Rosenbaum et al., 1994), it is imperative that these risk factors, along with other combat-related risk factors, such as the timing and number of deployments, be included in future studies of the active duty female's IPV experience within the military.

\section{Practice Implications}

An emerging body of research is beginning to identify different patterns of IPV, some of which look quite different from one another in terms of the demographic and psychosocial risk factors involved. These studies have led to a more complex understanding of both the 
female and male IPV experience. Clinicians conducting IPV assessments need to ask the necessary questions to first obtain an understanding of what pattern of violence is occurring. In addition to the violence factors explored in this study (type, level, frequency and direction, physical consequences) clinicians need to explore the emotional consequences and motives to get a complete and accurate understanding of the pattern of violence experienced. Certain risk factors, such as histories of child sexual abuse, including level of the severity of the abuse experienced, and depression, also demand more exploration in any IPV assessment involving a female client (civilian or military), given the consistent associations found with certain patterns of violence. Exploring and addressing these risk factors may be critical to achieving successful treatment outcomes for particular patterns of violence.

New treatment models may also be needed to respond to certain patterns of violence and the associated risk factors found in this study. One of the most utilized IPV interventions, the Deluth Model, assumes a pattern of male to female unilateral violence and focuses on changing male attitudes toward violence and teaching men the skills necessary to relate in nonviolent ways (Pence \& Paymar, 1993). While the Deluth Model may be an appropriate intervention for the male civilian spouses who reportedly committed unilateral violence toward their enlisted wives in our study, it does not address bidirectional patterns of IPV or the risk factors that we found to be associated with these patterns. Although several treatment models involving couple intervention have been shown to be effective for couples engaging in minor bidirectional violence, they are not deemed appropriate for severe bidirectional violence (O’Leary, Heyman, \& Neidig, 1999; Stith, Rosen, McCollum, $\&$ Thomsen, 2004). Our findings suggest that the enlisted female's involvement in severe bidirectional violence is very different than their involvement in minor bidirectional violence. The significant associations found in our study between a severe bidirectional pattern of violence and the risk factors of depression and childhood sexual abuse suggest that this group of women may need a very different treatment formulation.

\section{Future Research}

Intervention research is needed to better understand what kinds of approaches should be used in addressing the different patterns of unilateral and bidirectional violence for both civilian and female military populations. In order to do this type of intervention research, more consensus must be reached among researchers on what factors should be used in the identification of the different patterns of IPV so that the findings can be more easily interpreted and compared. Based on what we have learned in this study, including its limitations, it is our recommendation that, at a minimum, type, level, frequency, direction, physical impact, psychological impact, and motive should be included in the identification of the pattern of violence. In order to replicate findings across studies, it is clear that more work needs to be done to create meaningful violence groups that are not only valid and reliable, but acceptable and workable for all researchers in this field.

Our study findings represent the state of IPV patterns and their association with established IPV risk factors for enlisted females married to civilian males immediately prior to the U.S. military engagement in the Afghanistan and Iraq conflicts. How the prevalence rates for the different patterns of IPV found in this study may have changed since these conflicts began is an important area for future study. Equally important is the need to understand if and how the risk factor associations found in this study may have changed for enlisted females following their deployment to these areas and the impact of risk factors such as combat-related PTSD and TBI on the IPV pattern and risk factor landscape. 


\section{NOTES}

1. In 2006 (Forgey \& Badger, 2006), we reported that, according to the enlisted female's reports, $40 \%$ of the sample was comprised of nonviolent couples, $36 \%$ of the sample engaged in bidirectional violence of equivalent severity levels, a further $9 \%$ engaged in bidirectional but at different levels of severity, and unilateral violence, in which one partner was the sole perpetrator, was committed by the civilian spouse in $11 \%$ of the sample, compared to $3 \%$ by the enlisted female. This analysis resulted in 13 pattern categories. In order to conduct meaningful further analyses, and after much discussion and preliminary analysis, we reduced the number of groups to six without losing important conceptual distinctions about partner violence. Since bidirectional violence was a major interest in this analysis, we chose not to collapse all bidirectional violence, regardless of type, level of severity, or equivalence, into one category. Since at least $86 \%$ of both spouses committed minor psychological aggression, its existence was not a criterion for any group membership. Therefore, some members in all groups may have engaged in minor psychological aggression. Group membership was determined by the most severe form of violence in which the person engaged.

2. We removed "Made my partner have sex without a condom," one of three items in the Minor Sexual Coercion subscale, since its appropriateness to these married couples was dubious and inclusion could result in a questionably high prevalence.

3. Paygrades for enlisted personnel (nonofficer) range from E-1 to E-9.

\section{REFERENCES}

Barnett, O. W., \& Fagan, R. W. (1993). Alcohol use in male spouse abusers and their female partners. Journal of Family Violence, 8(1), 1-25.

Beckham, J. C., Feldman, M. E., Kirby, A. C., Hertzberg, M. A., \& Moore, S. D. (1997). Interpersonal violence and its correlates in Vietnam veterans with chronic posttraumatic stress disorder. Journal of Clinical Psychology, 53(8), 859-869.

Beere, C. A., King, D., Beere, D., \& King, L. (1984). The sex-role egalitarianism scale: A measure of attitudes toward equality between the sexes. Sex Roles, 10, 563-567.

Bell, N. S., Hartford, T. C., McCarroll, J. E., \& Senior, L. (2004). Drinking and spouse abuse among U.S. Army soldiers. Alcoholism: Clinical and Experimental Research, 28(12), 1890-1897.

Bernard, J., Bernard, S., \& Bernard, M. (1985). Courtship violence and sex typing. Family Relations, 34, 573-576.

Bernard, M., \& Bernard, J. (1983). Violent intimacy: The family as a model for love relationships. Family Relations, 32, 283-293.

Bernstein, D. P., \& Fink, L. (1998). Childhood Trauma Questionnaire (CTQ) Manual. San Antonio, TX: The Psychological Corporation.

Bernstein, D. P., Fink, L., Handelsman, L., Foote, F., Lovejoy, B. S., Wenzel, K., et al. (1994). Initial reliability and validity of a new retrospective measure of child abuse and neglect. American Journal of Psychiatry, 151(8), 1132-1136.

Bostock, D. J., \& Daley, J. G. (2007). Lifetime and current sexual assault and harrassment victimization rates of active-duty United States air force women. Violence Against Women, 13, 927-944.

Caetano, R., Ramisetty-Mikler, S., \& Field, C. A. (2005). Unidirectional and bidirectional intimate partner violence among White, Black and Hispanic couples in the United States. Violence and Victims, 20(4), 393-417.

Campbell, J. C., Garza, M. A., Gielen, A. C., O'Campo, P., Kub, J., Dienemann, J., et al. (2003). Intimate partner violence and abuse among active duty military women. Violence Against Women, 9(9), 1072-1093.

Cantos, A., Neidig, O., \& O'Leary, K. D. (1994). Injuries of women and men in a treatment program for domestic violence. Journal of Family Violence, 9(2), 113-124. 
Capaldi, D., \& Owen, L. (2001). Physical aggression in a community sample of at-risk young couples: Gender comparisons for high frequency, injury and fear. Journal of Family Psychology, 15(3), 425-440.

Carroll, E. M., Rueger, D. B., Foy, D. W., \& Conahoe, C. P. (1985). Vietnam combat veterans with posttraumatic stress disorder: An analysis of marital and cohabitating adjustment. Journal of Abnormal Psychology, 94(3), 329-337.

Cohen, R. A., Rosenbaum, A., Kane, R. L., Warnken, W. J., \& Benjamin, S. (1999). Neuropsychological correlates of domestic violence. Violence and Victims, 14(4), 397-411.

Crossman, R., Stith, S., \& Bender, M. (1990). Sex role egalitarianism and marital violence. Sex Roles, 22, 293-303.

Field, C. A., \& Caetano, R. (2005). Longitudinal model predicting mutual partner violence among White, Black and Hispanic couples in the United States general population. Violence and Victims, 20(5), 499-512.

Forgey, M. A., \& Badger, L. (2006). Patterns of intimate partner violence among married women in the military: Type, level, directionality and consequences. Journal of Family Violence, 21(6), 369-380.

Hamberger, L. K., \& Potente, T. (1994). Counseling heterosexual women arrested for domestic violence. Violence Against Women, 3, 401-423.

Hansen, C., \& Summers, K. B. (2005). A considerable sacrifice: The costs of sexual violence in the U.S. Armed Forces. Yale Manifesta, 1, 38-43.

Heyman, R. E., \& Neidig, P. H. (1999). A comparison of spousal aggression prevalence rates in U.S. Army and civilian representative samples. Journal of Consulting and Clinical Psychology, 67(2), 239-242.

Hoge, C. W., Castro, C. A., Messer, S. C., McGurk, D., Cotting, D. I., \& Koffman, R. L. (2004). Combat duty in Iraq and Afghanistan, mental health problems, and barriers to care. New England Journal of Medicine, 351(17), 1798-1800.

Hotaling, G. T., \& Sugarman, D. B. (1986). An analysis of risk markers in husband to wife violence: The current state of knowledge. Violence and Victims, 1, 101-124.

Kernsmith, P. (2005). Exerting power or striking back: A gendered comparison of motivations for domestic violence perpetration. Violence and Victims, 20(2), 173-185.

King, L. A., \& King, D. W. (1997). Sex-Role Egalitarianism Scale: Development, properties, and recommendations for future research. Psychology of Women Quarterly, 21, 71-87.

Kwong, M. J., Bartholomew, K., \& Dutton, D. G. (1999). Gender differences in patterns of relationship violence in Alberta. Canadian Journal of Behavioural Science, 31, 150-160.

Langhinrichsen-Rohling, J., Neidig, P. H., \& Thorn, G. (1995). Violent marriages: Gender differences in levels of current violence and past abuse. Journal of Family Violence, 10, 159-176.

Locke, H. J., \& Wallace, K. M. (1959). Short marital adjustment and prediction tests: Their reliability and validity. Marriage and Family Living, 21, 251-255.

Magdol, L., Moffitt, T. E., Caspi, A., Newman, D. L., Fagan, J., \& Silva, P. A. (1997). Gender differences in partner violence in a birth cohort of 21-year olds: Bridging the gap between clinical epidemiological approaches. Journal of Consulting and Clinical Psychology, 6, 68-78.

Magdol, L., Moffitt, R. E., Caspi, A., \& Silva, P. A. (1998). Developmental antecedents of partner abuse: A prospective-longitudinal study. Journal of Abnormal Psychology, 107(3), 375-389.

Marsh, N. V., \& Martinovich, W. M. (2006). Executive dysfunction and domestic violence. Brain Injury, 20(1), 61-66.

Marshall-Mies, J. C. (1996). 1995 Survey of Army Families III—Special Gender Analysis (Summary Report). Alexandria, VA: Army Personnel Survey Office: U.S. Army Research Institute.

McCarroll, J. E., Thayer, L. E., Liu, X., Newby, J. H., Norwood, A. E., Fullerton, C. S., et al. (2000). Spouse abuse recidivism in the U.S. Army by gender and military status. Journal of Consulting and Clinical Psychology, 68, 521-525.

McCarroll, J. E., Ursano, R. J., Fan, Z., \& Newby, J. (2004). Patterns of mutual and nonmutual spouse abuse in the U.S. Army (1998-2002). Violence and Victims, 19(4), 453-468. 
McCarroll, J. E., Ursano, R. J., Liu, X., Thayer, L. E., Newby, J. H., Norwook, A. E., et al. (2000). Deployment and the probability of spousal aggression by U.S. Army soldiers. Military Medicine, $165,41-44$.

Moffitt, T. E., Caspi, A., Krueger, R. F., Magdol, L., Margolin, G., Silva, P. A., et al. (1997). Do partners agree about abuse in their relationship? A psychometric evaluation of interparnter agreement. Psychological Assessment, 9(1), 47-56.

O’Leary, K. D., Arias, I., \& Samios, M. (1987). Prevalence and correlates of physical aggression during courtship. Journal of Interpersonal Violence, 2(1), 82-90.

O’Leary, K. D., Heyman, R. E., \& Neidig, P. H. (1999). Treatment of wife abuse: A comparison of gender specific and couples approaches. Behavior Therapy, 30, 475-505.

O’Leary, K. D., Malone, J., \& Tyree, A. (1994). Physical aggression in early marriage: PreRelationship and relationship effects. Journal of Consulting and Clinical Psychology, 62(3), 594-602.

Orcutt, H. K., King, L. A., \& King, D. W. (2003). Male-perpetrated violence among Vietnam veteran couples: Relationships with veteran's early life characteristics, trauma history, and PTSD symptomatology. Journal of Traumatic Stress, 16(4), 381-390.

Pan, H. S., Neidig, P. H., \& O'Leary, K. D. (1994). Predicting mild and severe husband to wife physical aggression. Journal of Consulting and Clinical Psychology, 62(5), 975-981.

Pence, E., \& Paymar, M. (1993). Education groups for men who batter: The Deluth model. New York: Springer.

Rosenbaum, A., Hoge, S. K., Adelman, S., Warnken, W. J., William, J., Fletcher, R., et al. (1994). Head injury in partner-abusive men. Journal of Consulting and Clinical Psychology, 62, $\underline{1187-1193 .}$

Rosenfeld, L., \& Jarrard, M. (1985). The effects of perceived sexism in female and male college professors on students' descriptions of classroom climate. Communication Education, 34, 205-213.

Schuerger, J., \& Reigle, N. (1988). Personality and biographic data that characterize men who abuse their wives. Journal of Clinical Psychology, 44, 75-81.

Selzer, M., Vinokur, A., \& Van Rooijen, L. (1975). A self administered Short Michigan Alcoholism Screening Test (SMAST). Journal of the Studies of Alcohol, 36, 117-126.

Shumacher, J., Feldbau-Kohn, S., Slep, A., \& Heyman, R. (2001). Risk factors for male to female physical abuse. Aggression and Violent Behavior, 6(2-3), 281-352.

Stith, S. M. (1986). Police officer response to marital violence predicted from officer's attitude, stress and marital experience: A path analysis. Dissertation Abstracts International, 47(7), 240-252.

Stith, S. M., \& Farley, S. C. (1993). A predictive model of male spousal violence. Journal of Family Violence, 8(2), 183-201.

Stith, S. M., Rosen, K. H., McCollum, E. E., \& Thomsen, C. J. (2004). Treating intimate partner violence within intact couple relationships: Outcomes of multi-couple versus individual couple therapy. Journal of Marital and Family Therapy, 30(3), 305-318.

Straus, M. A. (1990a). Measuring intrafamily conflict and violence: The conflict tactics (CT) Scales. In M. A. Straus \& R. J. Gelles (Eds.), Physical violence in American families (pp. 403-434). New Brunswick, NJ: Transaction Books.

Straus, M. A. (1990b). New scoring methods for violence and new norms for the Conflict Tactics Scales. In M. A. Straus \& R. J. Gelles (Eds.), Physical violence in American families: Risk factors and adaptations to violence in 8,145 families (Appendix B, pp. 535-559). New Brunswick, NJ: Transaction Books.

Straus, M. A., Hamby, S. L., Boney-McCoy, S., \& Sugarman, D. B. (1996). The revised Conflicts Tactics Scale (CTS2): Development and preliminary psychometric data. Journal of Family Issues, 17, 283-316.

Temple, J. R., Weston, R., \& Marshall, L. L. (2005). Physical and mental health outcomes of women in non-violent, unilaterally violent, and mutually violent relationships. Violence and Victims, 20(3), 335-360. 
Tjaden, P., \& Thoennes, N. (2000). Prevalence and consequences of male to female and female to male intimate partner violence as measured by the National Violence Against Women Survey. Violence Against Women, 6, 142-161.

Vivian, D., \& Langhinrichsen-Rohling, J. (1994). Are bidirectionally violent couples mutually victimized?: A gender-sensitive comparison. Violence and Victims, 9, 107-124.

Warden, D. (2006). Military TBI during the Iraq and Afghanistan wars. Journal of Head Trauma Rehabilitation, 21(5), 398-402.

Williams, S. L., \& Frieze, I. H. (2005). Patterns of violent relationships, psychological distress, and marital satisfaction in a national sample of men and women. Sex Roles, 52(11/12), 771-784.

Zung, W. W. (1965). A self rating depression scale. Archives of General Psychiatry, 12, 63-70.

Acknowledgments. This research was supported by Henry Jackson Foundation for the Advancement of Military Medicine, Contract \# 12726. We gratefully acknowledge the support and assistance of James McCarroll and John Newby of the Uniformed Services University of the Health Sciences and members of the U.S. Army Family Advocacy Research Subcommittee.

Correspondence regarding this article should be directed to Mary Ann Forgey, PhD, Graduate School of Social Service, Fordham University, 113 West 60th Street. New York, NY 10023. E-mail: Forgey@ fordham.edu 